\title{
Rehabilitación actual de los Studia Humanitatis. Una nota a propósito del humanista Leon Battista Alberti
}

\author{
Present Rehabilitation of Studia Humanitatis. \\ A Note on Humanist Leon Battista Alberti
}

JÉSSICA SÁNCHEZ ESPILLAQUE*

\begin{abstract}
Resumen: En la presente nota se reflexiona, con motivo de la publicación en castellano de la obra de Massimo Marassi Metamorfosis de la historia. El Momus de L. B. Alberti, sobre la actual necesidad de volver a pensar la validez filosófica de los llamados studia humanitatis.

Palabras clave: Studia humanitatis, humanismo, historia, retórica, metáfora.
\end{abstract}

\begin{abstract}
The present note is a reflection on the need to reconsider the philosophical validity of studia humanitatis nowadays, on occasion of the launching in Spanish of the work of Massimo Marassi Metamorfosis de la historia. El Momus de L.B. Alberti.
\end{abstract}

Keywords: Studia humanitatis, humanism, history, rhetoric, metaphor.

\section{Ernesto Grassi y la filosofía humanista}

La publicación en castellano de la obra de Massimo Marassi Metamorfosis de la historia. El Momus de L. B. Alberti ${ }^{1}$ nos ha motivado una reflexión acerca de la necesidad actual de una revisión filosófica de los llamados studia humanitatis. La editorial Anthropos (con la colaboración de la Fundación Studia Humanitatis de Zúrich) ha sido la encargada de publicar, en su colección Autores, Textos y Temas. Humanismo, dirigida por Emilio Hidalgo-Serna y José M. Sevilla, este interesante estudio dedicado al pensamiento del humanista italiano

Fecha de recepción: 02/01/2013. Fecha de aceptación final: 28/01/2014.

* Profesora PSI de la Universidad de Sevilla, desarrolla su labor investigadora y docente en el Departamento de Metafísica y Corrientes Actuales de la Filosofía, Ética y Filosofía Política de la Facultad de Filosofía (jsanchez17@us.es). Es miembro del Grupo de Investigación del P.A.I. “Ontología, Racionalidad y Praxis" (Cód. HUM-389). Sus investigaciones se centran en torno al problema de las Humanidades, el Humanismo renacentista y la filosofía de Ernesto Grassi. En esta línea, entre sus publicaciones más recientes destacan: El problema histórico-filosófico del humanismo retórico renacentista, presentación de Miguel A. Pastor, Sevilla: Fénix Editora (Colección Mínima del CIV), 2009, 149 pp.; Ernesto Grassi y la filosofía del humanismo, presentación a cargo de Emilio Hidalgo-Serna, Sevilla: Fénix Editora (Colección Biblioteca Viquiana n. 3), 2010, 224 pp.

1 M. Marassi: Metamorfosis de la historia. El Momus de L. B. Alberti, Prefacio de Emilio Hidalgo-Serna, tr. esp. de J. Navarro Pérez, Barcelona, Anthropos, 2008. Éste es el título de la edición española de la obra de Marassi impresa originalmente en italiano en 2004. Cfr. M. Marassi: Metamofosi della storia. Momus e Alberti, Milán, Mimesis, 2004. Véase, además, nuestra reseña a la edición italiana de esta obra: J. Sánchez Espillaque: «Humanismo retórico y reflexión histórica», Cuadernos sobre Vico (Sevilla), 17-18 (2004-2005), pp. 463-465. 
del siglo XV, Leon Battista Alberti. La edición del texto, traducido por Jorge Navarro Pérez, cuenta con un prefacio de Emilio Hidalgo-Serna, presidente de la Fundación Studia Humanitatis. Hidalgo considera este trabajo como un intento destinado a descifrar algunas claves de la velada tradición humanista retórica del Renacimiento, siguiendo las líneas marcadas por Ernesto Grassi (1902-1991). Para acercarse, pues, al contexto teórico del que surge este estudio, conviene rememorar la filosofía de Grassi — que Marassi conoce muy bien² —, porque es el heterodoxo discípulo de Heidegger quien primero denuncia el olvido de la vertiente retórica del Humanismo renacentista italiano por parte de la tradición occidental. Grassi advierte que la mayoría de las obras de estos humanistas, del siglo XV fundamentalmente, habían sido consideradas de carácter meramente literario, pasando de este modo casi inadvertidas en la Historia de la Filosofía. Del mismo modo, critica el hecho de que tradicionalmente el Humanismo renacentista haya sido considerado sólo como un acontecimiento histórico (en el sentido de ser un mero «antecedente» de los planteamientos que, posteriormente, se desarrollarían en la Modernidad), ya que esa interpretación provocó una gran inconsciencia acerca de su importancia filosófica. A esta apreciación hay que añadir, además, que dicha visión tradicional del Humanismo es la que, según Grassi, habría conducido al propio Heidegger a autoproclamarse —erróneamente, a juicio del filósofo italiano- «antihumanista» ${ }^{3}$.

Para mostrar no solamente la importancia histórica del humanismo retórico renacentista sino, sobre todo, su trascendencia filosófica, Grassi plantea la necesidad de llevar a cabo una rehabilitación de esta tradición humanista, cuyo olvido, como nos muestra en sus obras $^{4}$, comienza a partir de Descartes. En opinión de Grassi, el filósofo francés rechaza la retórica como fuente de conocimiento verdadero, sobre la base de la convicción de que un pensamiento retórico (esto es, sustentado en imágenes y motivado por las pasiones humanas) resulta incapaz de alcanzar el rigor del pensamiento científico. Desde este planteamiento Descartes juzgaría que tanto la retórica como la historia, la filología y la poesía, esto es, los llamados studia humanitatis, habrían de quedar fuera del ámbito de la filosofía. Según el argumento cartesiano, no aportan claridad y distinción al pensamiento, sino que lo enturbian, al partir del sentido común y no de un proceso racional. A este respecto la actitud racio-

2 Massimo Marassi, discípulo y amigo de E. Grassi, se encarga de la edición italiana de sus obras para la Fundación Studia Humanitatis (Zúrich). Ya ha editado y, en algunos casos, traducido y prologado las siguientes obras de Grassi: Potenza dell'immagine. Rivalutazione della retorica (Nápoles, Guerini e Associati, 1989); Potenza della fantasia: per una storia del pensiero occidentale (Nápoles, Guida, 1990); La metafora inaudita (Palermo, Aesthetica Edizioni, 1990); Il dramma della metafora. Euripide, Eschilo, Sofocle, Ovidio (Nápoles, L'Officina Tipografica, 1992); Viaggiare ed errare. Un confronto con il Sudamerica (Nápoles, La Città del Sole, 1999); Retorica come filosofia. La tradizione umanistica (Nápoles, La Città del Sole, 1999); algunas de las cuales han sido publicadas en español por la Editorial Anthropos. Además, Marassi es el editor, junto con E. HidalgoSerna, de Studi in memoria di Ernesto Grassi (Nápoles, La Città del Sole, 1996, 2 vols.), donde se recogen las importantes aportaciones al Congreso Internacional celebrado en Ischia en 1993, en conmemoración del filósofo italiano. Recientemente ha sido publicada, bajo la dirección de Marassi, la edición italiana de los primeros escritos de E. Grassi: Primi scritti. 1922-1946, Nápoles, La Città del Sole, 2011, 2 vols.

3 Ernesto Grassi demostrará que tanto el humanismo retórico como el pensamiento de Heidegger poseen un elemento en común: la reivindicación del valor de la palabra poética como palabra originaria. De Ernesto Grassi en nuestra monografía: J. Sánchez Espillaque: Ernesto Grassi y la filosofía del Humanismo (Sevilla, Fénix Editora, 2010), donde se puede encontrar también una amplia bibliografía sobre el autor.

4 Cfr. la bibliografía de Ernesto Grassi en nuestra monografía: J. Sánchez Espillaque: Ernesto Grassi y la filosofía del Humanismo (Sevilla, Fénix Editora, 2010), donde se puede encontrar también una amplia bibliografía sobre el autor. 
nalista no habría hecho otra cosa que considerar la tradición humanista únicamente como un fenómeno de erudición. Con el cartesianismo, el pensamiento abstracto y apriórico es el que juzga qué debe ser considerado como científico y qué no. O lo que es lo mismo: una proposición dada sólo será científicamente válida cuando pueda ser deducida a partir de una primera verdad; es decir, a partir de un principio indubitable que por su naturaleza es universal y necesario. Todo lo que sea mutable y concreto quedará fuera de los límites epistémicos, puesto que no podrá ser deducido a partir de esa primera «Verdad» con mayúsculas. La tradición racionalista estaría eliminando de la esfera del pensamiento científico no sólo a la retórica o a la filología, sino también a la historia y a las posteriormente denominadas ciencias humanas. Frente a esta reductiva interpretación del conocimiento filosófico, Marassi considera el humanismo retórico como un pensamiento filosófico original y, lo que es aún más importante, como un pensamiento muy actual.

\section{Metamorfosis de la historia}

La Metamorfosis de la historia. El Momus de L. B. Alberti está compuesta por dos amplios capítulos y una breve introducción en la que el autor, ya desde el comienzo, logra entusiasmarnos con su mostración del papel que juega la retórica en la filosofía, no sólo dentro de la tradición humanista renacentista sino, también, en la actualidad. En el primer capítulo, titulado «Momo o de la experiencia de la historia», Marassi analiza minuciosamente tanto el Momus como aquellas obras de Leon Battista Alberti (así la imponente De re aedificatoria ${ }^{5}$ o I libri della famiglia ${ }^{6}$ ) en las que el humanista genovés realiza una defensa de la historicidad como elemento esencial del ser humano. En el segundo capítulo, «Metamorfosis y metáfora», el autor parte de la base del carácter metamórfico de la realidad y examina los rasgos fundamentales del discurso metafórico (y de su relación con el concepto de historia) como posible herramienta con que poder conocer el devenir de lo real.

El Momus de Alberti ha sido considerada una de las más sugestivas expresiones del Humanismo del siglo XV, a pesar de que la obra no tuvo gran difusión hasta un siglo más tarde. El uso del sarcasmo y la ironía con que Alberti es capaz de mostrarnos su pensamiento hacen del Momus una de las obras filosóficas más relevantes de su autor. Frente a lo que normalmente ha considerado la tradición histórico-filosófica, el humanista aparece en esta obra como un gran filósofo. En opinión de Marassi, el Momus albertiano ${ }^{7}$ no es un libro de buenos consejos (como parecería en una lectura superficial), sino un tratado ontológico cuya finalidad última es la de ordenar el mundo. «Alberti tendrá la pluma aguda del buen humanista pero, tras la broma de la fábula y con la aparente ligereza de una escritura dictada por la fantasía, está hablando de la prima philosophia» ${ }^{8}$. La tesis fundamental del Momus concluye lo siguiente: el hombre ha de hacerse cargo de su naturaleza corrupta, que habría provocado que el ser humano, a diferencia del resto de los animales, no posea una vida ya predeterminada sino que, inevitablemente, deba construírsela. ¿Cómo ha de

5 L. B. Alberti: L'architettura, tr. de Giovanni Orlandi, Milán, Il Polifilo, 1989.

6 L. B. Alberti: I libri della famiglia, en Opere volgari, vol. I, Bari, Laterza, 1960, pp. 1-341.

7 Obra en la que aparentemente el autor está reflexionando sobre las cualidades que debe poseer un príncipe para gobernar bien el Estado.

8 M. Marassi: Metamorfosis de la historia. El Momus de L. B. Alberti, cit., p. 22. 
ir elaborándose su vida el hombre?, cabría preguntarse. A través de una continua elección entre las posibilidades que le plantea la vida, cada ser humano va poco a poco haciéndose a sí mismo. En este sentido, para Alberti las acciones humanas no son buenas o malas en sí mismas, sino que dependen del modo en que se las utilice. Según Alberti, el hombre ha de actuar siempre de acuerdo con la virtud y buscar en sus acciones el bien común de la ciudad. Conforme a este primado, no extrañará el que el humanista haga una encendida defensa de la vida civil del hombre, destacando la notable labor que desempeña la familia en el desarrollo de la sociedad ${ }^{9}$. Una cuestión definidora del llamado «humanismo cívico», cuya característica fundamental consiste en la defensa del bien común como fin último de las acciones humanas. Desde esta perspectiva, se afirma que el ser humano sólo se perfecciona en sociedad, es decir, rodeado de otros hombres con los que tiene que aprender a convivir.

Las disertaciones que en este estudio sobre Alberti lleva a cabo el catedrático milanés nos invitan a reflexionar sobre algunas de las características fundamentales del Humanismo. Sin embargo, y como es obvio por razones de espacio, no podemos ocuparnos aquí de los pormenores de dicha meditación. Sí queremos, en cambio, señalar cómo Marassi se refiere a la importancia que en esa «nueva época» comenzó a tomar la historiografía. De hecho, como advierte ya Nicolás Maquiavelo, la historia se convierte en «maestra de la vida». De ahí la presentación de las vidas de hombres ilustres, que aparecen como ejemplos (exemplum) a seguir. Éstos tienen la intencionalidad de ayudar al hombre a discernir entre el bien y el mal, «entendidos ya no como valores absolutos a los que referirse, sino como fruto de elecciones y decisiones concretas ${ }^{10}$. Así, la historia aparece como tutora del ser humano, ayudándole a obrar bien a través de la visión de los actos que en otro tiempo hombres óptimos realizaron, o de actos deplorables indignos de ser imitados. Esta cuestión nos conduce a reflexionar acerca del concepto humanista de imitatio (del que también se ocupa Marassi), el cual, lejos de reducirse a una concepción pasiva, supone el establecimiento de una actividad creadora (inventio) del individuo. Desde este punto de vista se afirma que, cuando los humanistas imitaban a los antiguos, en realidad estaban tomando conciencia de sí mismos. De este modo, la lectura de los clásicos habría inducido en el lector la toma de conciencia de su temporalidad, o sea, la conciencia de su naturaleza histórica le habría hecho más humano. Puede decirse que, con respecto al conocimiento de la Antigüedad greco-romana, la diferencia fundamental entre el humanista y el medieval no se halla sólo en un conocimiento más profundo de los clásicos. Es sobre todo la conciencia histórica lo que hizo al humanista acercarse a los antiguos de un modo distinto a como lo habían hecho los medievales. Los humanistas pensaban que a través de la lectura de las obras clásicas el hombre lograría conocerse mejor a sí mismo. Del mismo modo, Marassi cree que con la obra de Alberti «no nos encontramos ante una mera reformulación de doctrinas antiguas, de alusiones escondidas, de citas irónicas e interpoladas» ${ }^{11}$, sino ante un planteamiento completamente nuevo que,

9 En palabras de Marassi: «Los diálogos de I libri della famiglia exponen un sentido del hombre que ya no reposa en una definición abstracta, sino en la presentación de personalidades ilustres, de ejemplos insignes, de hombres con un nombre específico que hacen nacer una nueva época», M. Marassi: op. cit., p. 44.

10 Ibidem.

11 M. Marassi: op. cit., pp. 45-46. 
haciendo uso del pensamiento antiguo, logra exponer un pensamiento original y novedoso. Alberti es capaz de alcanzar en su obra un equilibrio entre imitación e innovación, entre imitatio e inventio.

¿En qué consistiría, pues, la novedad de este pensamiento humanista? Básicamente en que para Alberti el hombre es un compuesto de alma, cuerpo y tiempo ${ }^{12}$. Es decir, el tiempo se representa, junto a la tradicional concepción de alma-cuerpo, como parte constitutiva de la naturaleza humana. Por eso las cosas no son buenas o malas en sí mismas, sino que dependen de la consideración humana en cada momento. Por consiguiente, apreciamos que la conciencia histórica (encarnada en la veritas filia temporis) es ya uno de los grandes descubrimientos del Humanismo. Otra conquista humanista, de la que también se hará eco Alberti, está relacionada también con la importancia que va a adquirir la historicidad: es la supremacía de la actividad práctica. Para los humanistas la historia es obra del hombre, ésta nace de la acción humana, acaece «como narración de las obras y de las virtudes de hombres específicos, que son amigos, parientes, antes que como producto de los profesionales de la historiografía» ${ }^{13}$. El hombre ha nacido para hacer cosas y no para ser ocioso. Este reconocimiento de la historicidad humana del que parte Alberti le permitirá además establecer el conocimiento humano como un saber histórico. De ahí que el autor prefiera la fábula, y no el tratado filosófico, para exponer su nuevo pensamiento. Con la narración fantástica se hace posible expresar el pensar humano como una continua conquista. La tradición humanista establece que sólo mediante la actividad metafórica es posible manifestar aquella verdad originaria (acerca de la historicidad del ser humano) que no puede ser demostrada racionalmente. Esto es, el recurso de la fábula permite a $\mathrm{L}$. B. Alberti revelar una realidad multiforme, cambiante e incluso contradictoria (la realidad humana), que, por la misma razón, sería inútil tratar de aprehenderla a través de conceptos puros y a priori.

Lo que de nuevo, magistralmente, nos viene a mostrar Marassi aplicando la lectura de Grassi es que la fábula y el uso de metáforas no es un artificio retórico sino una verdadera filosofía. Si bien no sólo L. B. Alberti había hecho este uso de un pensamiento y un lenguaje metafóricos (ya que también los encontramos, por ejemplo, en Juan Luis Vives y su Fabula de homine o en Elogio de la locura de Erasmo), sí fue uno de los primeros en formularlo. Con ello vemos cómo una de las razones por las que la filosofía humanista habría pasado posteriormente casi inadvertida y velada habría sido, precisamente, por este uso de un lenguaje metafórico e imaginativo. Uno de los motivos que habrían provocado el posterior olvido de la tradición humanista sería el hecho de que este pensamiento no se expresara mediante una sistematización filosófica, como había sido lo propio de la Escolástica y, posteriormente, de la filosofía moderna. Por eso, parece una vana pretensión buscar una filosofía sistemática y apriorística en el humanismo retórico, puesto que jamás la encontraremos, no al menos como se ha entendido tradicionalmente.

12 M. Marassi: op. cit., p. 63.

13 Ibid., p. 62. 


\section{Humanismo filosófico-retórico}

Decíamos al comienzo de esta nota que la tesis fundamental que mantiene Marassi en esta obra viene a recoger el testigo de una de las ideas principales defendidas por el filósofo milanés Ernesto Grassi: el humanismo retórico renacentista es verdadera filosofía. Una defensa que Grassi fundamenta en la tesis de la preeminencia del lenguaje metafórico sobre el lenguaje racional, que humanistas como Dante, Mussato, Petrarca, Salutati, Bruni o Poliziano habían afirmado. Esta teoría grassiana acerca de la primacía del pensamiento metafórico sobre el racional podemos sintetizarla del siguiente modo. Como ya hemos observado, todo discurso demostrativo, racionalista, consiste en la deducción de unas conclusiones a partir de unas premisas ya dadas. Éstas se fundan en unos principios que, por su naturaleza, han de ser indemostrables (puesto que si se demostrasen a través de otros principios entonces - como dice Vico en su Scienza Nuova- no serían unos «primeros» principios). Si ello es así, la tarea que se nos plantea — dirá Grassi- no es otra que la de averiguar qué tipo de discurso proporciona al pensamiento racional los argumentos, es decir, los primeros principios a través de los cuales éste comienza a deducir. Parece obvio que tal necesario discurso originario no puede ser apodíctico-demostrativo porque, como ya hemos dicho, se trata de los principios elementales y básicos (archai) y, por tanto, no pueden ser derivados, a su vez, de otros más originales. Para Grassi, este logos discursivo es el discurso retórico que, a diferencia del racional, no es demostrativo sino indicativo, o sea, mostrativo; aunque no por ello sinónimo de irracional. ¿Dónde encontramos un discurso de estas características?: en la retórica. Luego la retórica cumple una función primordial aportando al pensamiento racional los argumentos para la deducción. De aquí concluye este filósofo que el pensamiento retórico, tal y como había mostrado Giambattista Vico y toda la tradición humanista italiana anterior, tiene preeminencia sobre el pensamiento racional, ya que la «indicazione» precede a la «interpretazione» ${ }^{14}$. Este razonamiento grassiano es el que, a nuestro parecer, asume y le va a permitir a Marassi poder concluir lo siguiente:

Por eso, la metáfora ya no es sólo una figura, ya no desempeña sólo una función retórica, ya no es simplemente un ornamento del discurso, sino que se presenta como el pensamiento mismo, como su sustancia, como lo que el concepto no consigue quitar o sosegar, pues es su origen profundo, el todo del que procede ${ }^{15}$.

Sólo a través de un discurso metafórico, en el que la palabra adquiere sobre todo flexibilidad, es posible expresar y comprender el carácter metamórfico de la realidad. Para poder llegar a esta conclusión ha sido necesario rechazar la interpretación tradicional de Humanismo que lo considera simplemente un giro antropológico en la cultura. Se ha de superar, por tanto, aquella concepción que reduce todo el Humanismo antrópico a una nueva metafísica de lo Ente (ahora el Hombre). Es posible una imagen diferente del

14 E. Grassi: Potenza dell'immagine. Rivalutazione della retorica, cit., p. 84.

15 M. Marassi: Metamorfosis de la historia. El Momus de L. B. Alberti, cit., pp. 121-122. Las cursivas son nuestras. 
humanismo entendiéndolo como un nuevo modo de hacer filosofía hermanada ésta con la filología y la retórica. Conforme con la tesis de Marassi, «las metáforas representan los elementos fundamentales del lenguaje filosófico capaces de abrir un mundo cuya realidad existe sólo en el lenguaje» ${ }^{16}$. Hay que recordar que el propio Grassi había criticado —en no pocos diversos lugares- la errada interpretación antropológica del Humanismo. En su opinión,

con Mussato, con C. Salutati, con Valla, con Pontano se inicia un pensamiento completamente alejado de la metafísica tradicional y que plantea una problemática nueva: no aquella de la verdad lógica sino la de la realidad en su manifestarse en la historicidad. El pensamiento del Renacimiento — con su platonismo y aristotelismointerrumpirá esta tradición del pensamiento 'ingenioso' de un Vives, de un Gracián y de los teóricos italianos del Manierismo: Tesauro y Pellegrini ${ }^{17}$.

Dicho en otras palabras, la tesis principal desarrollada por Grassi en la mayoría de sus obras (y que, a nuestro juicio, reelabora inteligentemente y con acierto Marassi en la suya), sería la expuesta a continuación. Frente a la interpretación de numerosos historiadores que han negado la existencia de una filosofía propia en el Renacimiento, con el Humanismo renacentista aparece un nuevo modo de filosofar — distinto del de la tradición metafísica occidental - basado y centrado en el problema de la palabra en vez de en el problema del ente. Grassi afirma que frente a la problemática tradicional, fundamentada en el problema de la verdad, el Humanismo parte del problema de la palabra, haciendo de la filosofía una filosofía eminentemente retórica. No obstante, dicha filosofía retórica, metafórica, imaginativa, queda ensombrecida a finales del siglo XV con la llegada del neoplatonismo. La línea del pensamiento humanista metafísico y neoplatonista pone fin — según Grassi — al original y «verdadero» Humanismo, esto es, al humanismo retórico. De hecho, la continuación renacentista de la tradición platónica y del neoplatonismo constituye, según lo expuesto, el comienzo del olvido de la tradición humanista retórica. Un olvido que se acrecentará, como ya hemos comentado, con la llegada del pensamiento racionalista de Descartes y que, salvo algunas excepciones (desde Vives o Nizolio hasta Gracián o Vico, entre los principales) continuará hasta el pensamiento contemporáneo dominando e imponiendo su perspectiva idealista, abstracta, apriorística y pretenciosamente «demostrativa».

\section{Rehabilitación del humanismo}

En consonancia con la rehabilitación de esa tradición humanista velada, la obra de Massimo Marassi creemos que ofrece, en realidad, un análisis crítico de la época actual, en la que parece que sólo deba llamarse «científico» a aquello que puede ser medido y cuantificado. Una acertada crítica, por tanto, al tipo dominante de mentalidad reduccionista moderna capaz de afirmar que conocer una cosa es captar su utilidad técnica. En palabras de Marassi: «Una

16 Ibid., p. 162.

17 E. Grassi: «Il concetto di storia umana nell'elogio della pazzia di Erasmo», Res Publica Litterarum, The University of Kansas, VI (1983), pp. 145-153, p. 153. La traducción es nuestra. 
vez más, la historia nos hace reflexionar sobre la imposibilidad de gobernar la totalidad de los asuntos humanos con un metro tan rígido como el del cálculo» ${ }^{18}$.

En conclusión, el autor nos muestra en estas lúcidas páginas el concepto humanista de la historia, a saber: un concepto metafórico que concibe el devenir histórico como la característica fundamental del ser humano. De ahí que, en su opinión, el hombre, dado su carácter histórico y temporal, no pueda ser medido con un «metro» tan ceñido como el cientificista moderno.

En última instancia, lo que Marassi está planteando, en armonía con el programa grassiano, es la necesidad de una rehabilitación del humanismo retórico como alternativa del racionalismo abstracto. Su estudio de la obra de Alberti ofrece un ejemplo de esa validez filosófica que prima la realidad humana y la historia. Nos muestra, de este modo, que es posible establecer desde el Humanismo un nuevo modo de filosofar esencialmente histórico, un pensamiento metafórico que estrecha la relación entre filosofía y retórica. Marassi asienta y establece la importancia del conocimiento que, basándose en una de las tesis centrales del Humanismo (esto es, la comunión entre res y verba), no separa teoría y práctica, logos y pathos. Lo cual supone, como hemos observado, superar la interpretación de la metáfora como un elemento puramente formal del discurso y verla, en cambio, como un medio con el que poder conocer la estructura siempre cambiante de la realidad, la metamorfosis de la historia.

El magnífico estudio del profesor milanés no sólo propone una novedosa lectura de Leon Battista Alberti, sino que a través de su consistente y meditada interpretación revitaliza la tradición del humanismo retórico, que ha estado oculta incluso dentro del Humanismo renacentista. Con ello, se nos ofrece la posibilidad de una más rica «expresión filosófica», como bien advertimos ya desde el inicio de la obra, cuando, introduciéndonos en ella, dice su autor:

Parece ser, por tanto, que asistimos a un rhetorical turn (como nos recuerdan las obras de Heinrich Lausberg, los volúmenes del Historisches Wörterbuch der Rhetorik, dirigidos por Gert Ueding, y la imponente Historie de la rhétorique dans l'Europe moderne, dirigida por Marc Fumaroli) que se ha producido siempre, desde el mundo bíblico, desde Grecia, desde la tradición latina, que prosigue en el Humanismo y en el Renacimiento, y que resurge indemne en el pensamiento contemporáneo tras siglos de una «razón» monopolizada lógica y abstractamente como forma única de la expresión filosófica ${ }^{19}$.

18 M. Marassi: Metamorfosis de la historia. El Momus de L. B. Alberti, cit., p. 4.

19 M. Marassi: op. cit., p. 5. 